\title{
Caso para diagnóstico
}

\author{
Case for diagnosis
}

Isabella Brasil Succi ${ }^{1}$

\section{HISTÓRIA DA DOENÇA}

Paciente do sexo masculino, 10 anos, pardo, estudante, procurou o ambulatório de dermatopediatria com queixa de mancha branca no rosto há um mês. Negava doenças prévias, exceto episódios de febre alta durante a infância. Ao exame dermatológico, notou-se mácula hipocrômica de aproximadamente $1,0 \mathrm{~cm} \times 0,5 \mathrm{~cm}$ na região pré-auricular direita. Apresentava, também, cabelos esparsos, finos, rarefação de sobrancelhas (Figura 1), hipodontia parcial (ausência de incisivos mediais e laterais inferiores, com caninos cônicos) (Figura 2) e pele seca.

Solicitou-se uma avaliação oftalmológica, que não apresentou alterações, e uma radiografia panorâmica, que evidenciou ausência de germes dentários $18,17,15,14,25,27,28,38,34,32,31,41,42,45,48$ e conoidismo no 12, 11, 21, 22 (Figura 3). O teste do iodo para avaliar a sudorese foi negativo.

A queixa principal do paciente, compatível com pitiríase alba, se resolveu após cerca de oito semanas, com o uso de filtro solar e hidratação cutânea.

\section{COMENTÁRIOS}

A síndrome de Christ-Siemens-Touraine (displasia ectodérmica hipoidrótica) é caracterizada por ausência parcial ou completa de glândulas sudoríparas, hipotricose e hipodontia. Tem herança recessiva ligada ao X. A incidência é de aproximadamente 1:100.000 nascidos, sendo que $90 \%$ dos pacientes são do sexo masculino. A síndrome completa não ocorre em mulheres ${ }^{1-3}$ mas as mães destas crianças são portadoras do gene causal e têm manifestações discretas, como áreas localizadas de hipoidrose, cabelos ou
Elisa Fontenelle ${ }^{2}$

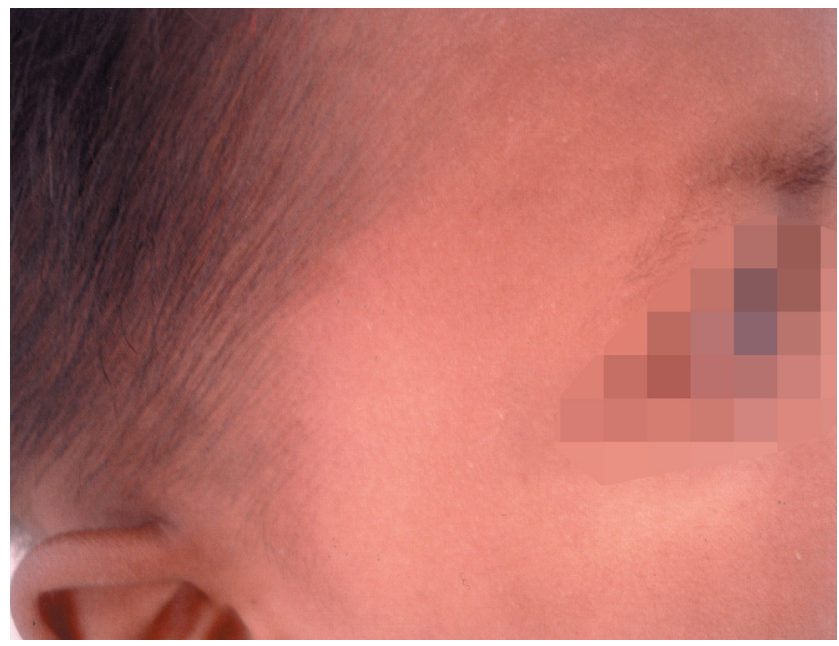

Figura 1: Displasia ectodérmica hipoidrótica - cabelos esparsos, finos e rarefação de sobrancelhas

supercílios esparsos, leite escasso, alterações dentárias4 e anormalidades dermatoglíficas. ${ }^{1}$ Os recémnatos afetados podem apresentar membrana coloide ou descamação cutânea tipo ictiose. ${ }^{5}$ Pacientes acometidos têm aparência típica e se parecem mais uns com os outros do que com seus próprios irmãos. ${ }^{2}$

As alterações clínicas compreendem: sudorese ausente ou reduzida, hipotricose, anodontia total ou parcial. Na apresentação completa da síndrome, podem-se encontrar: rugas frontais, nariz em sela, lábios espessos evertidos, orelhas grandes, tíbia proeminente e pele seca. ${ }^{1}$ A capacidade reduzida de perspiração resulta em hipertermia e os pacientes mani-

Recebido em 06.02.2007

Aprovado pelo Conselho Consultivo e aceito para publicação em 12.03.08.

* Trabalho realizado no Instituto de Dermatologia Prof. Azulay - Santa Casa da Misericórdia do Rio de Janeiro - Rio de Janeiro (RJ), Brasil.

Conflito de interesse: Nenhum / Conflict of interest: None

Suporte financeiro: Nenhum / Financial funding: None

Pós-graduanda em Dermatologia do Instituto de Dermatologia Prof. Azulay - Santa Casa da Misericórdia do Rio de Janeiro - Rio de Janeiro (RJ), Brasil. Chefe do ambulatório de Dermatologia Pediátrica do Instituto de Dermatologia Prof. Azulay - Santa Casa da Misericórdia do Rio de Janeiro - Rio de Janeiro (RJ), Brasil. 


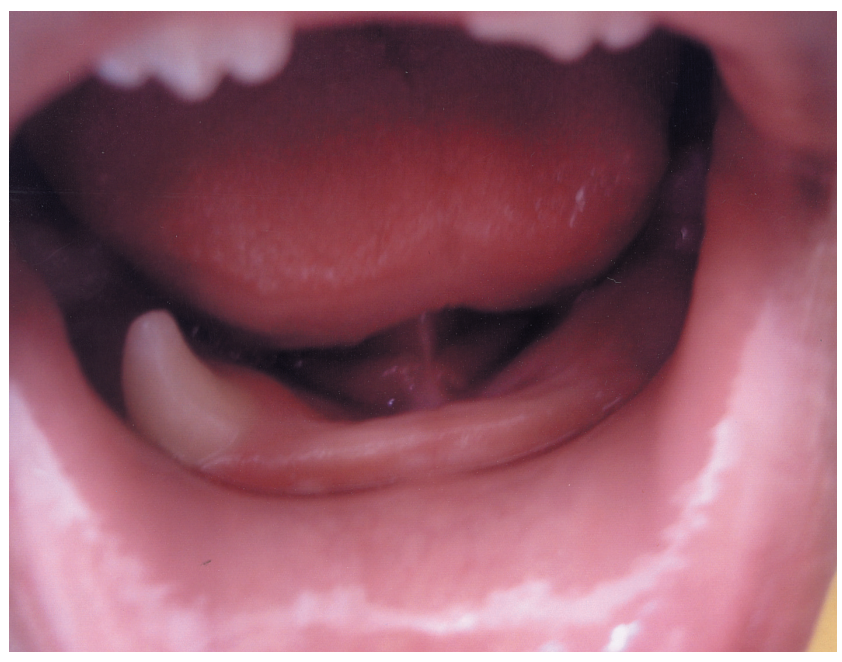

Figura 2: Ausência de incisivos mediais e laterais inferiores

festam febre intermitente, em especial, durante o clima quente e após exercícios ou refeições. A alopecia é uma das primeiras características que chamam a atenção, mas raramente é total. Os cabelos são esparsos, finos, secos, permanentemente curtos e pouco pigmentados. $^{2}$ As sobrancelhas são esparsas ou ausentes, mas os cílios são normais, em geral. Os pêlos corporais podem estar ausentes ou esparsos. Os dentes incisivos e/ou caninos são caracteristicamente cônicos e pontiagudos e são a chave para o diagnóstico da síndrome, podendo ser a única anormalidade óbvia. ${ }^{1}$ A primeira e a segunda dentições são afetadas. ${ }^{5}$ A mandíbula é normal, mas a gengiva pode ser atrófica. A boca pode ser seca, pela hipoplasia de glândulas salivares, favorecendo o aparecimento de cáries mais precocemente. Pode haver rinite atrófica, descarga nasal persistente e formação de crostas, infecções respiratórias crônicas e problemas

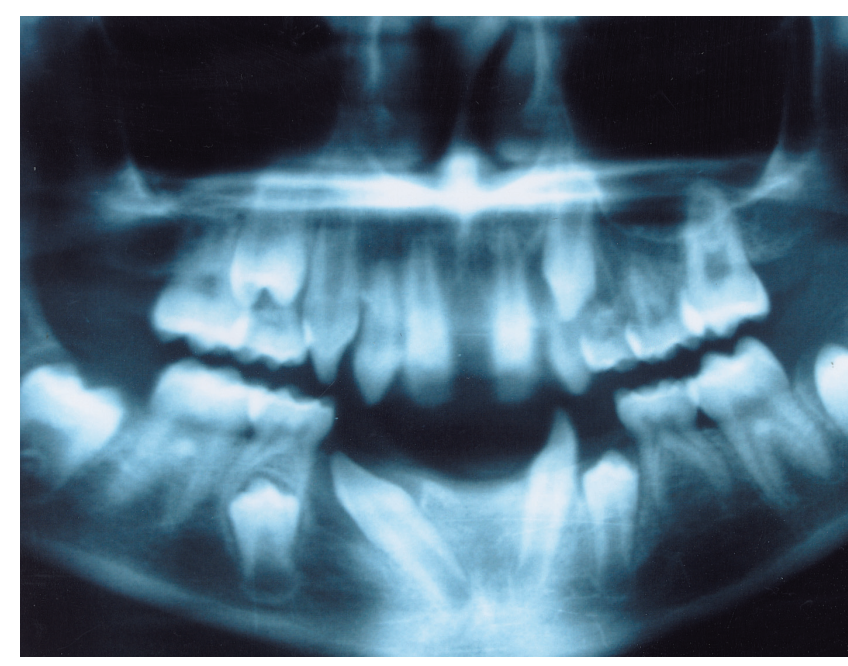

FigURA 3: Radiografia panorâmica: ausência de germes dentários e conoidismo

auditivos. Eczema atópico e asma podem estar presentes. A redução de glândulas na mucosa do trato gastrointestinal pode resultar em disfagia, estomatite e diarréia. Anormalidade ungueal ocorre em $50 \%$ dos casos $^{1}$ e se caracteriza por unhas finas e enrugadas. Anormalidades oculares são incomuns, embora opacidades lenticulares e corneanas possam ocorrer, além da ausência do orifício lacrimal. ${ }^{3}$

O diagnóstico deve ser suspeitado diante de descamação ao nascimento e/ou hipertermia inexplicada. A fácies característica é patognomônica. ${ }^{1}$

O tratamento baseia-se em banhos frios, ambiente fresco, roupas leves e restrição de excessos físicos. ${ }^{1-3}$ Visitas ao dentista devem ser regulares $\mathrm{e}$ pode haver intervenção dentária, como próteses ou implantes dentários, para preservar a função e a estética. Colírios e irrigação nasal podem compensar a secreção glandular reduzida. ${ }^{2}$ 
Resumo: A síndrome de Christ-Siemens-Touraine (displasia ectodérmica hipoidrótica) é uma síndrome rara, caracterizada pela tríade de sudorese reduzida ou ausente, hipotricose e dentição defeituosa. Bossas frontais proeminentes, nariz em sela, lábio inferior espesso e queixo pontudo fazem com que os pacientes tenham uma fácies característica e semelhante. A síndrome completa ocorre em homens, visto tratar-se de herança recessiva ligada ao $\mathrm{X}$.

Palavras-chave: Dermatopatias genéticas; Displasia ectodérmica; Síndrome de Christ-Siemens-Touraine

Abstract: Christ-Siemens-Touraine syndrome (hypohidrotic ectodermal dysplasia) is a rare syndrome characterized by the triad of absent or reduced sweating, hypotrichosis, and defective dentition. The prominent forehead, saddle nose, thick lower lip and pointy chin produce a distinctive facies. The full syndrome only occurs in men as it is an X-linked recessive condition.

Keywords: Ectodermal dysplasia; Ectodermal dysplasia 1, anhidrotic; Skin diseases, genetic

\section{REFERÊNCIAS}

1. Harper JI, Trembath RC. Ectodermal Dysplasias. In: Burns T, Breathnach S, Cox N, Griffiths C, editors. Rook's Textbook of Dermatology. 7th ed. London: Blackwell Publishing; 2004. p. 40-2.

2. Paller AS, Mancini AJ. Disorders of hair and nail. In: Paller AS, Mancini AJ. Hurwitz clinical pediatric dermatology. 3rd ed. Philadelphia: Elsevier Saunders; 2006. p. 153-5.

3. Palit A, Inamadar A. Christ-Siemens-Touraine syndrome. Pediatr Dermatol. 2006;23:396-8.

4. Sampaio SAP, Rivitti EA. Doenças poiquilodérmicas e displasias ectodérmicas. In: Sampaio SAP, Castro RM, Rivitti EA. Dermatologia. 2 ed. São Paulo: Artes Médicas; 2000. p. 799.

5. Sybert VP, Zonana J. Ectodermal dysplasias. In: Bologna JL, Jorizzo JL, Rapini RP. Dermatology. London: Mosby; 2003. p. 906-7.

ENDEREÇO PARA CORRESPONDÊNCIA / MAILING ADDRESS ISABELLA BRASIL SUCCI

Av. Visconde de Pirajá, 82/805

Ipanema-Rio de Janeiro-RJ

22410-000 Rio de Janeiro RJ

Tel./fax: 2125210191

E-mail:ibsucci@unisys.com.br

Como citar este artigo/How to cite this article: Succi IB, Fontenelle E. Caso para diagnóstico. Displasia ectodérmica: Síndrome de Christ-Siemens-Touraine. An Bras Dermatol. 2009;84(2):194-6. 